\title{
Vitamin D Status and its Association with BMI in Obese and Non-Obese Children in a Tertiary Care Level Hospital
}

\author{
Sudhir Shantilal Mavadia ${ }^{*}$, Kuldeep Singh ${ }^{2}$ \\ ${ }^{1 *}$ Assistant Professor, ${ }^{2}$ Senior Resident, \\ Department of Paediatrics, TMMC \& RC, Moradabad, UP, INDIA.
}

\begin{abstract}
Introduction: Vitamin $\mathrm{D}$ deficiency has become a worldwide problem; moreover it has been found associated with obesity in adults as well as in children. Inactivity of children and lack of sunlight exposure induce the vitamin $D$ deficiency through decreasing the bioavailability of vitamin $D$. Vitamin $D$ deficiency is more pronounced in obese in comparison of none obese due mal absorption of calcium. Relationship of vitamin D and obesity is not clear yet. Therefore the present study was designed to evaluate the relation of vitamin $\mathrm{D}$, serum calcium and BMI in obese children.

Material and Method: The study included two groups of children one group was consisted 74 obese children 6 to 16 yrs of age while second group included 63 non-obese children of 6 to $16 \mathrm{yrs}$ age. All the obese and non-obese children were recruited from the nearby area of Teerthanker Mahaveer University Moradabad. p-value $<0.05$ was considered statistically significant.
\end{abstract}

Result: Serum calcium was significantly low in obese group $6.8 \pm 0.4 \mathrm{mg} / \mathrm{dl}$ in comparison of non-obese $9.6 \pm 0.3 \mathrm{mg} / \mathrm{dl}$ $(p<0.001)$. Further, Mean serum $25-\mathrm{OH}$-vit $D$ in the obese group $12.6 \pm 4.6 \mathrm{ng} / \mathrm{ml}$ was significantly lower $(P<0.0001)$ than that of the non-obese group $19.6 \pm 7.5 \mathrm{ng} / \mathrm{ml}$. Total cholesterol $(212.1 \pm 34.8 \mathrm{v} / \mathrm{s} 172 \pm 29.2, \mathrm{p}<0.001)$, triglycerides (119.6 \pm $24.4 \mathrm{v} / \mathrm{s} 90.2 \pm 18.7, \quad p<0.001)$, were significantly higher in obese children in comparison of non-obese children. Though,

\section{INTRODUCTION}

42 million of infants and children were overweight in 2013and if the current trends continue more than 70 million children will be suffering with obesity. ${ }^{1}$ Obesity has become a pandemic throughout the world. Moreover it is rising day by day in every country of world. Further risk of elevate lipid profile, cardio vascular diseases, morbidity and mortality is associated with obesity. ${ }^{2}$ Obesity is one of the major contributing factor of onset and progression various autoimmune disorders. Adipokines secreted from adipose tissue have been found associated with pathogenesis of autoimmune diseases. ${ }^{3}$ Serum calcium is one of the most important sources for bones growth in children. ${ }^{4} 99 \%$ of total calcium of body found in bones whereas vitamin $D$ increase the renal absorption of filtered calcium. ${ }^{5}$ Vitamin $D$ deficiency has become a worldwide problem; moreover it has been found associated with obesity in adults as well as in children. ${ }^{6,7}$ Inactivity of children and lack of sunlight exposure induce the vitamin $D$ deficiency through decreasing the bioavailability of vitamin $D .{ }^{8}$ high density lipids $(35.4 \pm 12.5 \mathrm{v} / \mathrm{s} 49.7 \pm 14.2$, $p<0.001)$ was significantly low in obese children whereas low density lipids showed an insignificant difference between both groups.

Conclusion: Vitamin D insufficiency and serum calcium deficiency are common among obese children in comparison of non-obese children. However, poor vitamin D status is an effect or cause of obesity is not clear yet. Nevertheless, most of the studies suggest that either oral vitamin $D$ intake or weight loss can improve the vitamin D level in obese children.

Key words: BMI, Serum calcium, Vitamin D, Obese.

*Correspondence to:

Dr. Sudhir S Mavadia, Assistant Professor, Department of Paediatrics, TMMC \& RC, Moradabad, UP, INDIA.

Article History:

Received: 02-05-2016, Revised: 08-05-2016, Accepted: 19-05-2016

\begin{tabular}{|l|c|}
\hline \multicolumn{2}{|c|}{ Access this article online } \\
\hline Website: & Quick Response code \\
www.jimrp.com & \\
\hline DOI: & \\
10.21276/ijmr. 2016.2.3.024 & \\
\hline
\end{tabular}

Vitamin $\mathrm{D}$ deficiency is more pronounced in obese in comparison of none obese due malabsorption of calcium. ${ }^{9}$ Obesity leads to accumulation of fat mass which further increase adipose tissue; moreover adipose tissue acts as endocrine gland and secrets various bioactive factors known as adipokines.

Vitamin $D$ is a fat soluble vitamin which is stored in fat cell of the body therefore, serum concentration of vitamin $D$ is inversely related to body mass. ${ }^{10}$ Decrease of vitamin $D$ significantly increase the lipid profile and cardio metabolic risk. ${ }^{11}$ Vitamin $D$ is inversely related to obesity in adults. ${ }^{12}$

Moreover, decrease of vitamin $\mathrm{D}$ leads to decrease absorption as well bone turnover of calcium which further leads to reduce bone mineral density; however decrease bone mineral density is associated with risk of fracture as well as osteoporosis. ${ }^{13}$ Nevertheless, relationship of vitamin $D$ and obesity is not clear yet. Therefore the present study was designed to evaluate the relation of vitamin $\mathrm{D}$, serum calcium and $\mathrm{BMI}$ in obese children. 


\section{MATERIAL AND METHODS}

\section{Study Population}

A cross sectional type of study included two groups of children one group was consisted of 74 obese children from 6 to $16 \mathrm{yrs}$. of age while second group included 63 non-obese children of 6 to 16 yrs age. All the obese and non-obese children were recruited from the Teerthanker Mahaveer University, Moradabad, UP, INDIA.

Purpose of research was clearly narrated to every child and his/her, parents/ guardian. Written informed consent was taken from the parents or guardians of every child before taking part in this study.

Inclusion criteria for obese children was body mass index (BMI) is at or above $85^{\text {th }}$ percentile of their age whereas for non-obese BMI is at or above $5^{\text {th }}$ percentile and below $85^{\text {th }}$ percentile of their age. ${ }^{14}$ Rest of the inclusion and exclusion criteria were same for either group.

All the participants were non-alcoholic and none smoker. None of the child was suffering from any type of chronic disease including marasmus, tuberculosis, asthma, thyroid disorders etc. None of the child was on any type of medication or hormonal therapy.

\section{METHODOLOGY}

\section{Anthropometric Parameters}

Height: Height was measured to the nearest centimeter using a rigid stadiometer. ${ }^{15}$

Weight: Standard portable weighing machine was used to measure the weight. ${ }^{15}$

Body Mass Index: BMI was calculated using LMS method. ${ }^{16}$

\section{Biochemical Parameters}

Biochemical evaluations were done with fasting serum sample. Estimation of serum calcium level: Serum calcium level was measured by Arsenazo III Method. ${ }^{17}$

Estimation of Vitamin D level: Vitamin D was measured by Elisa method. ${ }^{17}$

Estimation of Lipid Profile: Lipid profile in that serum sample was measured by serum concentrations of following parameters.

- Serum concentration of total cholesterol was estimated by the enzymatic CHOD-POD method. ${ }^{17}$

- Serum concentration of triglycerides was measured by the GPO-PAP method. ${ }^{17}$

- Serum concentration of high density lipoprotein was measured by CHOD-POD/ Phosphotungstate method. ${ }^{17}$

- Serum concentration of low density lipoprotein was measured by using Friedewald's formula. ${ }^{17}$

Statistical Analysis

The obtained value of vitamin $\mathrm{D}$ was considered as following sufficiency, $25(\mathrm{OH}) \mathrm{D}$ of at least $75 \mathrm{nmol} / \mathrm{liter}(30 \mathrm{ng} / \mathrm{ml})$; insufficiency, less than $75 \mathrm{nmol} /$ liter $(30 \mathrm{ng} / \mathrm{ml})$; and deficiency, less than $50 \mathrm{nmol} /$ liter $(20 \mathrm{ng} / \mathrm{ml})$.

One way ANOVA was used to compare the values of Vitamin D, serum calcium, lipid profile and BMI in both group. Further, Pearson correlation coefficient was used on data of either group to evaluate weather $B M l$ is correlated with vitamin $D$, serum calcium and lipid profile. p-value < 0.05 was considered statistically significant. IBM SPSS Statistics 21 manufactured by IBM USA was used for entire calculations.

Table 1: Mean anthropometric data of the study and control groups.

\begin{tabular}{lccc}
\hline Parameters & Obese $(n=74)$ & Non-obese $(n=63)$ & $P$ \\
\hline Age $($ years \pm SD) & $13.4 \pm 3.6$ & $13.8 \pm 3.1$ & $<0.84^{*}$ \\
Height $(\mathrm{cm})$ & $137.4 \pm 8.8$ & $141.9 \pm 10.8$ & $<0.41^{*}$ \\
Waist circumference $(\mathrm{cm})$ & $94.5 \pm 11.3$ & $70.2 \pm 13.2$ & $<0.005^{* \star}$ \\
Weight & $58.7 \pm 5.8$ & $41.8 \pm 4.2$ & $<0.001^{* \star *}$ \\
BMl $(\mathbf{k g} / \mathrm{m} 2)$ & $31.09 \pm 5.4$ & $20.8 \pm 3.7$ & $<0.001^{* \star *}$ \\
BMl\% & $98.6 \pm 15.3$ & $77.8 \pm 13.3$ & $<0.001^{* \star *}$ \\
\hline
\end{tabular}

SD: standard deviation, BMI: body mass index, BMI SDS: body mass index standard deviation score, BMI\%: body mass index percentage. ${ }^{*}=$ non-significant, ${ }^{* *}=$ significant, ${ }^{* *}=$ highly significant.

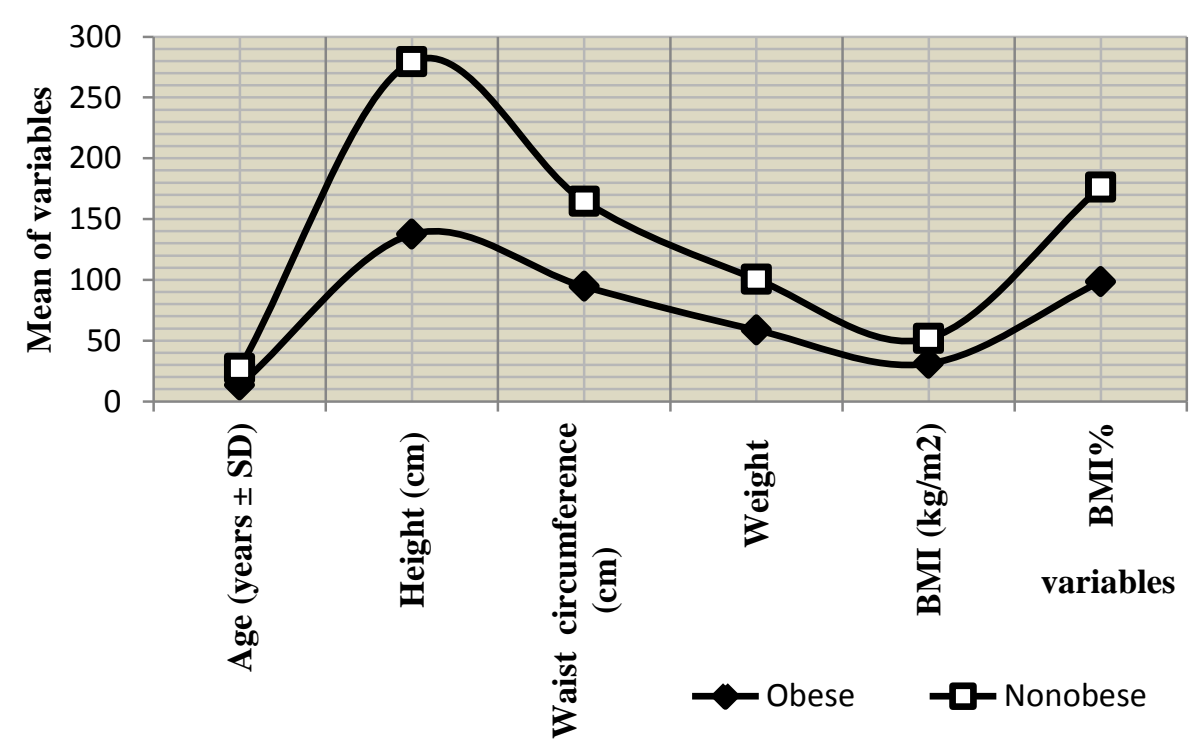

Figure 1: Mean anthropometric data of the study and control groups. 
Table 2: Metabolic markers of the study and control groups.

\begin{tabular}{lccc}
\hline & Obese $(n=118)$ & Nonobese $(n=118)$ & P \\
\hline Glucose $(\mathbf{m g} / \mathrm{dL})$ & $98.4 \pm 12.5$ & $86.4 \pm 9.6$ & $<0.27^{*}$ \\
Serum Calcium & $4.3 \pm 1.9$ & $3.3 \pm 2.1$ & $<0.001^{* * *}$ \\
25-OHD (ng/dL) & $12.6 \pm 4.6$ & $19.6 \pm 7.5$ & $<0.001^{* * *}$ \\
Lipid Profile & & & \\
$\quad$ Triglyceride $(\mathrm{mg} / \mathrm{dL})$ & $119.6 \pm 24.4$ & $90.2 \pm 18.7$ & $<0.001^{* * *}$ \\
LDL cholesterol $(\mathrm{mg} / \mathrm{dL})$ & $103.2 \pm 26.4$ & $90.6 \pm 22.9$ & $<0.001^{* * *}$ \\
HDL cholesterol $(\mathrm{mg} / \mathrm{dL})$ & $35.4 \pm 12.5$ & $49.7 \pm 14.2$ & $<0.001^{* * *}$ \\
Total cholesterol $(\mathrm{mg} / \mathrm{dL})$ & $212.1 \pm 34.8$ & $172 \pm 29.2$ & $<0.001^{* * *}$ \\
\hline \multicolumn{2}{r}{${ }^{*}=$ non-significant, ${ }^{* *}=$ significant, ${ }^{* * *}=$ highly significant. } &
\end{tabular}

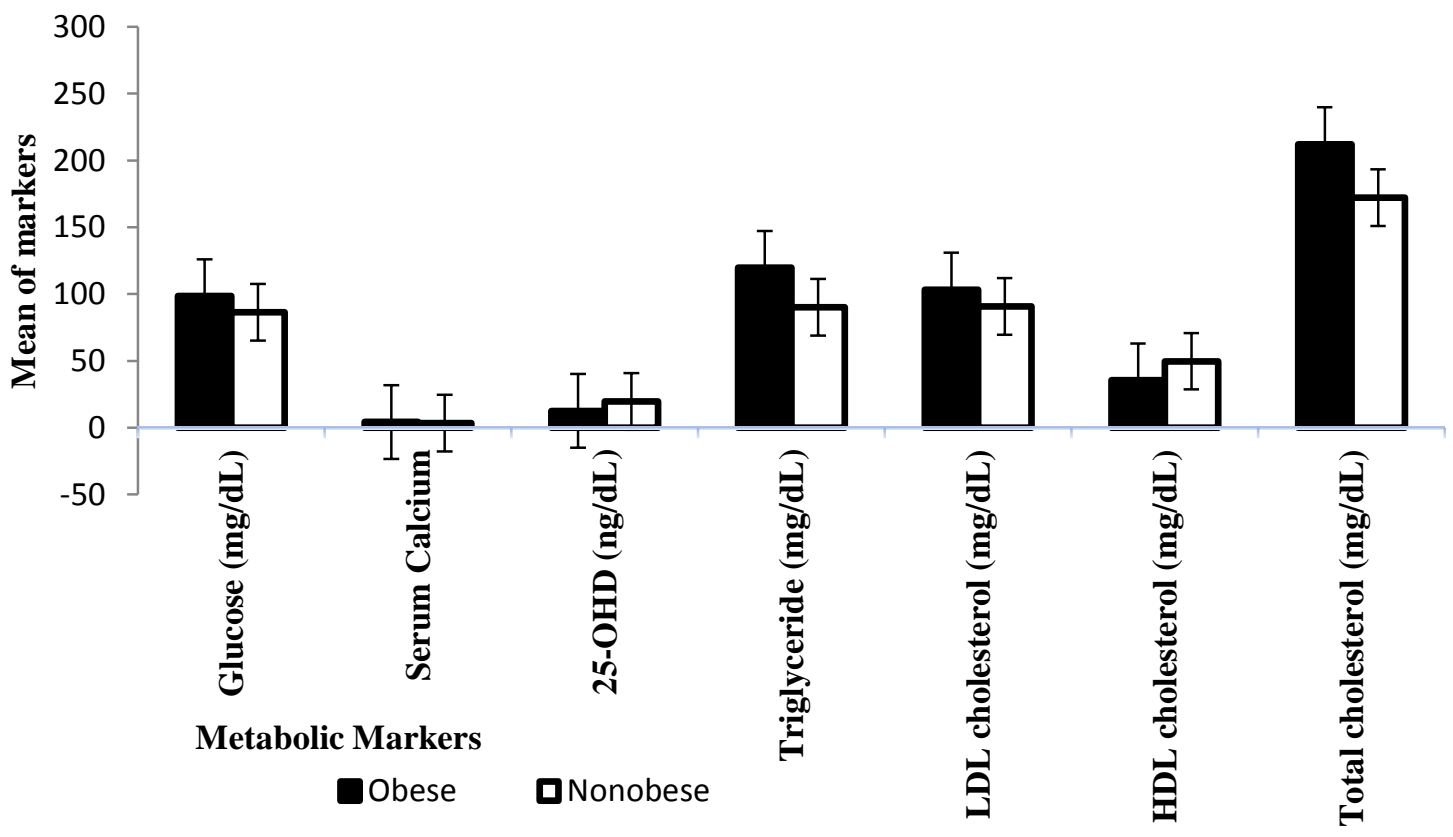

Figure 2: Metabolic markers of the study and control groups.

\section{RESULTS}

Table 1 shows that there was no significant difference between the age and height of both group children. However, a significant deference between two groups was observed for waist circumferences $(p<0.001)$ as well as Weight $(p<0.001)$. A significant deference of BMl $10.29 \pm 1.7 \mathrm{~kg} / \mathrm{m}^{2}$ between two groups was recorded. Further, there was statistically significant deference $20.8 \pm 2 \%$ between BMI percent of both groups.

Table 2 shows that there was an insignificant difference between fasting blood sugar level of obese children and non-obese children group. However, serum calcium was significantly low in obese group $6.8 \pm 0.4 \mathrm{mg} / \mathrm{dl}$ in comparison of non-obese $9.6 \pm 0.3 \mathrm{mg} / \mathrm{dl}$ $(p<0.001)$. Further, Mean serum $25-\mathrm{OH}$-vit $D$ in the obese group12.6 $\pm 4.6 \mathrm{ng} / \mathrm{ml}$ was significantly lower $(P<0.0001)$ than that of the non-obese group $19.6 \pm 7.5 \mathrm{ng} / \mathrm{ml}$. Total cholesterol $(212.1 \pm 34.8 \mathrm{v} / \mathrm{s} 172 \pm 29.2, p<0.001)$, triglycerides (119.6 \pm 24.4 $\mathrm{v} / \mathrm{s} 90.2 \pm 18.7, p<0.001)$, were significantly higher in obese children in comparison of non-obese children.(Table \& Figure 1,2) Though, high density lipids (35.4 $\pm 12.5 \mathrm{v} / \mathrm{s} 49.7 \pm 14.2$, $p<0.001)$ was significantly low in obese children whereas low density lipids showed an insignificant difference between both groups. There was a negative association ( $r=-0.41 ; P<0.0001)$ between serum calcium and $\mathrm{BMI}$ whereas a negative correlation $(r=-0.46$; $\mathrm{P}<0.0001$ ) between $25-\mathrm{OH}$-vit $\mathrm{D}$ and $\mathrm{BMI}$.

\section{DISCUSSION}

Obesity has become the foremost risk factor for various diseases including bone fracture and osteoporosis. ${ }^{18}$ Obese subjects are more susceptible to develop vitamin $D$ deficiency. ${ }^{19}$ We have observed significant low level of calcium in obese children in comparison of non-obese children. Our result is consistent to previous studies of Caruth BR et al and Cunha KDA et al. ${ }^{19,20}$ Normal level of serum calcium is essential to ensure the zenith bone mass development. However, decrease of serum calcium is associated with deficiency of vitamin $D$ which facilitates the absorption of calcium from intestine. Therefore, decrease of vitamin $D$ can lead to decrease serum calcium level..21,22 Decrease calcium level may have deep effects on neurological, renal, gastrointestinal functions as well as adverse effects on bone metabolism. Nonetheless, vitamin $D$ is required along with oral calcium to treat hypocalcaemia. ${ }^{23}$ Moreover, calcium rich diet reduce the body fat as increased level of calcitriol enhance the conversion of cortisone to cortisol in adipocytes via stimulating $11 \beta$ - hydroxysteroid dehydrogenase type 1 enzyme. ${ }^{19}$ Further, we have observed significant decrease of vitamin $D$ in obese children in comparison of non-obese children. (Table 1) Our findings are very similar to previous studies of Rajkumar $\mathrm{K}$ et al, Olson $\mathrm{ML}$ et al and Oleviera RM et al.24-26 Deficiency of vitamin D in obese children seems to be due to it's a lipid soluble vitamin and it is 
accumulated in adipose tissue. Moreover, adipocyte is now considered as endocrine gland secretes various types of enzymes like cytokines, adipokines etc helps in further decrease of vitamin D. ${ }^{27}$ Decrease vitamin $D$ level leads to reduce bone mineral density which further induces the risk of fracture as well as osteoporosis especially in obese people. ${ }^{28}$ Obesity in combination with vitamin $\mathrm{D}$ deficiency induces various health hazards including inflammation, reduced mineralization and compromised bone growth. ${ }^{21}$ Furthermore, our findings reveal that Vitamin $D$ is negatively correlated to BMI which is similar to previous studies of Cunha KDA et al. ${ }^{19}$ and Peterson CA et al29 as they have also observed the same correlation between vitamin $D$ and BMI. This negative correlation may be due to increased BMI is associated with increased amount of fat accumulation; therefore decrease bioavailability of vitamin D. ${ }^{30}$

On the other we recorded negative correlation of serum calcium and BMI which is similar to the findings of Cunha KDA et al and Caruth BR et al. ${ }^{19,20}$ This negative correlation between BMl and calcium suggest that decrease level of vitamin $D$ in obese children leads to reduce serum calcium level. Further, obesity effect bone metabolism via stimulating production of co inflammatory factors like cytokines which affects osteogenesis via increasing leptin secretion. ${ }^{31}$ Nonetheless, there is a significant difference in bone turnover of obese and non-obese children may be due to decreased of vitamin $\mathrm{D}$ and serum calcium. Moreover, we have recorded increased lipid profile in our study which is very similar to the previous studies of Friedland $O$ et al and Lima SC et al. ${ }^{32,33 .}$ Increased lipid profile might be due to increase body fat as well as weight. Moreover, increased lipid profile is directly related to increased blood pressure as well as high risk of cardiovascular diseases. 34,35 Previous studies have shown that increased lipid profile, hypocalcaemia and vitamin D deficiency are correlated as vitamin $D$ is fat soluble thus it is sequestered and stored in adipocytes as body fat increases. Further, decrease bioavailability of vitamin d leads increased appetite, accumulation of fat and decrease serum calcium level. However, supplementation of vitamin $\mathrm{D}$ and calcium can decrease the body fat. ${ }^{19,36}$

\section{CONCLUSION}

We conclude that vitamin $D$ insufficiency and serum calcium deficiency are common among obese children in comparison of non-obese children. However, poor vitamin D status is an effect or cause of obesity is not clear yet. Nevertheless, most of the studies suggest that either oral vitamin $D$ intake or weight loss can improve the vitamin $D$ level in obese children. Though, further researches are required to assess the status and mechanism of vitamin $\mathrm{D}$ deficiency in obese children.

\section{REFERENCES}

1. World Health Organization. Population-based approaches to childhood obesity prevention. Geneva: WHO Document Production Services; 2016.

2. Boudewijn K, Jan Willem F. Elte and Manuel Castro Cabezas Dyslipidemia in Obesity: Mechanisms and Potential Targets Nutrients 2013; 5: 1218-1240; doi:10.3390/nu5041218

3. Versini M, Jeandel PY, Rosenthal E, Shoenfeld Y Autoimmun Rev. Obesity in autoimmune diseases: not a passive bystander. 2014; 13(9): 981-1000. doi: 10.1016/j.autrev.2014.07.001.

4. Sarina S, Dietary Calcium Intake and Obesity. Fam Pract 2005;18:205-210.
5. Steven A, Lietman, M.D.1, Emily L. Germain-Lee, M.D.2, and Michael A. Levine, M.D.3 Hypercalcemia in Children and Adolescents. Curr Opin Pediatr. 2010; 22(4): 508-515.

6. Al- Musharf S, Al- Othman A, Al-Daghri NM, et al. Vitamin D deficiency and calcium intake in reference to increased body mass index in children and adolescents. Eur J Pediatr. 2012 ;171(7):1081-6. doi: 10.1007/s00431-012-1686-8.

7. Holick MF, Chen TC. Vitamin D deficiency: a worldwide problem with health consequences. Am J Clin Nutr.2008;87(4):1080-6.

8. Wortsman J, Matsuoka LY, Chen TC, Lu Z, Holick MF. Decreased bioavailability of vitamin D in obesity. Am J Clin Nutr 2000; 72: 690693.

9. N H Bell, E Sol, G Anne, et al. Evidence for Alteration of the Vitamin D-Endocrine System in Obese Subjects. J. Clin. Invest. 1985; 76: 370-373.

10. C Cristiana, P Jessica, P Sara, Vitamin D and Its Relationship with Obesity and Muscle. International Journal of Endocrinology.2014;11.

http://dx.doi.org/10.1155/2014/841248

11. NM Al-Daghri, Y Al-Saleh, N Aljohani, et al. Vitamin D Deficiency and Cardiometabolic Risks: A Juxtaposition of Arab Adolescents and Adults. PLoS One. 2015;10(7): 1315 . doi: 10.1371/journal. pone. 0131315

12. JP Shamik, E Marni, I Gabriel, et al. The Relationship between Obesity and Serum 1,25-Dihydroxy Vitamin D Concentrations in Healthy Adults The Journal of Clinical Endocrinology \& Metabolism 2004; 89(3):1196-1199.

13. Ardawi MS, Sibiany AM, Bakhsh TM, Qari MH, Maimani AA. High prevalence of vitamin $D$ deficiency among healthy Saudi Arabian men: relationship to bone mineral density, parathyroid hormone, bone turnover markers, and lifestyle factors. Osteoporos Int. 2012; 23(2):675-86. doi: 10.1007/s00198-011-1606-1.

14. Allison J, Nihiser, Sarah M, et al. Body Mass Index Measurement in Schools.. Journal of School Health d December. 2007; 77:10.

15. Sharma R, Sharma TK, Kaushik GG, Sharma S, Vardy Sk, Sinha M. Subclinical Hypothyroidism and its assosiaton with cardiovascular risk factors. Clin Lab. 2011; 57(9-10):719-24.

16. K Rajakumar, John D, Michael F, et al. Vitamin D Status and Response to Vitamin D3 in Obese vs. Non-obese African American Children. Obesity. 2008;16.

17. Burtis CA, Ashwood ER, Bruns DE. Teitz fundamentals of clinical chemistry.2008; 6:422-24.

18. Kelly $A C$, et al. Calcium intake, serum vitamin $D$ and obesity in children: is there an association? Rev Paul Pediatr. 2015;33(2):222229 .

19. Catherine A. Peterson, Aneesh K. Tosh, Anthony M. Belenchia. Vitamin $D$ insufficiency and insulin resistance in obese adolescents. Ther Adv Endocrinol Metab. 2014; 5(6): 166-189.

20. Carruth BR, Skinner JD. The role of dietary calcium and other nutrients in moderating body fat in preschool children. Int $\mathrm{J}$ Obes Relat Metab Disord. 2001;25:559-66.

21. Chapuy MC, Arlot ME, Duboeuf $F$, et al. Vitamin $D_{3}$ and calcium prevent fractures in elderly women. The New England Journal of Medicines. 2005; 27(3):1637-42.

22. John A Sunyecz. The use of calcium and vitamin $D$ in the management of osteoporosis. Ther Clin Risk Manag. 2008; 4(4): 827836. Published online 2008 Aug. PMCID: PMC2621390

23. David A Bushinsky, Rebeca D Monk. Calcium-The Lancet. 1998;352: 306-311.

24. Rajakumar K, John D. Fernstrom, Michael F. Vitamin D Status and Response to Vitamin D3 in Obese vs. Non-obese African American Children. Obesity 2008;16. 
25. Micah L. Olson, Naim M. Maalouf, Jon D. Oden, et al. Vitamin D Deficiency in Obese Children and Its Relationship to Glucose Homeostasis. Clin Endocrinol Metab, 2012, 97(1):279-285.

26. Oliveira RM, Novaes JF, Azeredo LM, Cândido AP, Leite IC. Association of vitamin $\mathrm{D}$ insufficiency with adiposity and metabolic disorders in Brazilian adolescents. Public Health Nutr. 2014;17(4):787-94. doi: 10.1017/S1368980013001225.

27. Catherine A Peterson. Vitamin D deficiency and childhood obesity: interactions, implications, and recommendations. Nutrition and Dietary Supplements. 2015:7 29-39.

28. Ardawi MS, Sibiany AM, Bakhsh TM, Qari MH, Maimani AA. High prevalence of vitamin $D$ deficiency among healthy Saudi Arabian men: relationship to bone mineral density, parathyroid hormone, bone turnover markers, and lifestyle factors. Osteoporos Int. 2012; 23(2): 675-86. doi: 10.1007/s00198-011-1606-1.

29. Catherine A. Peterson, Aneesh K. Tosh, and Anthony M. Belenchia. Vitamin $D$ insufficiency and insulin resistance in obese adolescents. Ther Adv Endocrinol Metab. 2014; 5(6): 166-189.

30. Carine M Lenders, Henry A Feldman, Emily Von Scheven, Relation of body fat indexes to vitamin $D$ status and deficiency among obese adolescents. Pediatric Research Network Obesity Study Group. Am J Clin Nutr 2009;90:459-67.

31. Dalfardi O, Jahandideh D, Omrani GH. The Correlation of Serum Calcium Level and Obesity; Is There any Explanation? GMJ. 2013;2(1):26-31.

32. Friedland $\mathrm{O}$, Nemet $\mathrm{D}$, Gorodnitsky N, Wolach B, Eliakim A. Obesity and lipid profiles in children and adolescents. J Pediatr Endocrinol Metab. 2002;15(7):1011-6.
33. Lima SC, Arrais RF, Sales CH, Almeida MG, et al. Assessment of copper and lipid profile in obese children and adolescents. Biol Trace Elem Res. 2006;114(1-3):19-29.

34. Borghi C. Interactions between hypercholesterolemia and hypertension: implications for therapy. Curr Opin Nephrol Hypertens. 2002;11(5): 489-96.

35. Neaton JD, Wentworth D. Serum cholesterol, blood pressure, cigarette smoking, and death from coronary heart disease: overall findings and differences by age for 316099 white men. Arch Intern Med 1992;152(1):56-64.

36. Schuch NJ, Garcia VC, Martini LA. Vitamin D and endocrine diseases. Arq Bras Endocrinol Metab. 2009;35:625-33

Source of Support: Nil. Conflict of Interest: None Declared.

Copyright: ( ) the author(s) and publisher. IJMRP is an official publication of Ibn Sina Academy of Medieval Medicine \& Sciences, registered in 2001 under Indian Trusts Act, 1882.

This is an open access article distributed under the terms of the Creative Commons Attribution Non-commercial License, which permits unrestricted non-commercial use, distribution, and reproduction in any medium, provided the original work is properly cited.

Cite this article as: Sudhir Shantilal Mavadia, Kuldeep Singh. Vitamin D Status and its Association with BMI in Obese and NonObese Children in a Tertiary Care Level Hospital. Int J Med Res Prof. 2016; 2(3):103-07. 